\title{
Advances in the Application of Nanofluids Molecular Dynamics in Oil and Gas Field Development
}

\author{
Yang Feng ${ }^{1,2,3}$, Jirui Hou ${ }^{1,2,3^{*}}$, Dongsen Wang ${ }^{4}$, Shuting Wang ${ }^{5}$, Hongda Hao ${ }^{6}$, Dansen Shang ${ }^{123}$, Jia \\ Wang ${ }^{1}$ \\ ${ }^{\text {I}}$ Enhanced Oil Recovery Institute, The Unconventional Oil and Gas Institute, China University of \\ Petroleum (Beijing), Beijing 102249, China \\ ${ }^{2}$ Basic Theory Laboratory of Improve Oil Recovery in Low Permeability Oil Field, Tertiary Oil Recovery \\ Key Laboratory, PetroChina, Beijing 102249, China \\ ${ }^{3}$ Oilfield Development Key Laboratory of MOE, Beijing 102249, China; \\ ${ }^{4}$ China National Offshore Oil Corporation Safety \& Technology Services Company Limited, Tianjin \\ 300450, China \\ ${ }^{5}$ State Key Laboratory of Heavy Oil Processing, China University of Petroleum, Beijing, Beijing 102249, \\ China \\ ${ }^{6}$ School of Petroleum Engineering, Changzhou University, Changzhou, Jiangsu 213164, China \\ *Corresponding Author.
}

\begin{abstract}
Molecular dynamic (MD) simulation has been widely applied to various technical fields, especially in oil-gas field development in recent years. The MD simulation of nanofluids is elaborated from the aspect of nanofluid properties research via $M D$, the self-assembling $M D$ simulation of nanoparticles at $O / W$ two-phase interface, and the flow simulation of nanofluids in microscopic pores. Finally, theoretical guidance is provided for the application of MD in oilfield development to foster strengths and circumvent weaknesses.
\end{abstract}

Keywords: Molecular dynamics simulation, nanofluids, viscosity, stability, self-assembly

\section{Introduction}

Low permeability oil and gas resources occupy an all-important position in the world oil and gas resources, and with the deepening of petroleum exploration degree, its proportion will continue to increase. However, there are significant differences in percolation mechanism, development mode, EOR method and economic benefits between low, medium and high permeability reservoirs. Low permeability reservoirs are characterized by difficulty in development, low recovery rate, poor benefits, and insufficient space for surfactant production. Scholars have found that nanofluid has great potential for enhanced recovery. Therefore, many scholars have carried out experimental and simulation studies on a series of problems related to nanofluid. However, due to the limitation of nanoparticles size, the experiment could not well explain the microscopic mechanism of nanofluid, so MD simulation became a good interpretation method.

In 1957, Alder and Wainwright [1] first studied the equation of state of gas and liquid by using MD under the hard ball model, thus creating a precedent for studying the macroscopic properties of matter by using MD simulation method. In the late 1980s, the rapid development of computer technology and the proposal and development of multi-body potential function injected new vitality into MD simulation technology, and provided theoretical and technical support for putting into use of nanofluid MD simulation in oil-gas field development. MD simulation can not only get the details of the motion of atoms, but also make intuitive observation like an experiment. We analyzed

ISSN: 0010-8189

(C) CONVERTER 2020

www.converter-magazine.info 
the properties of nanofluids, studied the self-assembled MD simulation of nanoparticles in O/W two-phase interface, and discussed the flow simulation of nanofluids in microscopic pores, providing guidance for the putting into use of nanofluid MD simulation in oil-gas field development and enhanced oil recovery.

\section{Nanofluid Properties MD Simulation}

Choi et al. [2] first putted forward the notion of nanofluid, which one is to disperse metal or nonmetal nano powder into water, alcohol, oil and other traditional heat transfer media to prepare uniform, stable and high thermal conductivity new heat transfer media. Nanofluids have huge application potential in energy, construction, information and other fields, so they have become a research focus on medicine, materials, physics, bilology, chemistry, heat transfer and other fields. The stability and viscosity of nanofluids are reviewed.

\subsection{Stability}

Nanoparticles dispersion stability in base is the foundation of all subsequent research, scholars have made a huge contribution for this in the experimental aspect, but in the use of MD study of nanofluids stability study is less, the stability of nanofluids is influenced by the following aspects: nanoparticles and base fluid interaction relations, the properties of nanoparticles, the size of nanoparticles morphology, temperature, and the add and type of dispersant.

Nanoparticles and base fluid interaction relations. Wang et al. [3] using the equilibrium MD simulation method, tracking $\mathrm{Cu}$ nanoparticles dispersed in the liquid $\mathrm{CO}_{2}$ each position of the solid and liquid molecules, they found that increasing gravity can make the solid particle surface between solid-liquid adsorption liquid molecules by the increase in the number, but don't change the thickness of liquid layer, they believe that increased gravity causes more liquid molecules to be absorbed around the solid particles, which prevents them from coming closer together and effectively prevents or delays agglomeration.

The stability of nanofluids formed by nanoparticles is also very different due to their different properties and morphology. Qin [4] pointed out that the larger the potential barrier between particles, the thermal motion of particles cannot overcome it, and particles are not easy to accumulate. The gravitational potential energy between particles is a significant cause for the agglomeration of particles in nanofluids, and the size of the barrier is a key factor affecting the stability of nanofluids. He believed that the Brownian force had an effect on the stability of nanofluids. The nanoparticles are suspended in the base fluid walked randomly under the action of the Brownian force, so that particles would not stand still in one place, so that the particles would not precipitate due to gravity. However, the particles collide with each other and get together to form particle clusters, which may meet and gather to form larger particle clusters. When the particle clusters reach a certain degree, they are easy to precipitate, which affects the stability and uniformity of nanofluids. The two-phase resistance impedes the movement of nanoparticles and makes them tend to be stationary, thus affecting the stability and uniformity of nanofluids. The counteracting force of gravity and buoyancy also affects the stability of nanofluids.

The addition of dispersants and the type of dispersants in nanofluids are also significant factors affecting the stability of nanofluids. Ling et al. [5] studied the result of surfactants on the dispersion stability of $\mathrm{Cu}-\mathrm{H}_{2} \mathrm{O}$ and $\mathrm{ZrO} 2-\mathrm{H}_{2} \mathrm{O}$ nanofluids through experiments and simulations. The result showed that adding surfactants could greatly improve the stability of nanofluids, and different surfactants had different effects on the stability, especially adding sodium dodecylbenzenesulfonate had the best effect. He found that stability of nanofluids increased first and then decreased with the increasing amount of surfactant added, indicating that excessive surfactant was not conducive to the improvement of nanofluid stability.

\subsection{Viscosity}

ISSN: 0010-8189

(C) CONVERTER 2020 
Adding nanoparticles to the liquid changes not only on the thermal conductivity of the liquid but also on its viscosity. The viscosity of nanofluid is mainly affected by the volume fraction of the particles in the nanofluid, nanoparticle size, aggregation and temperature. Most of the theoretical formulas for the general solid-liquid two-phase viscosity had evolved from Einstein's formula, the nanofluid viscosity calculation model is summarized below.

Table 1 Nanofluid viscosity calculation model table

\begin{tabular}{|c|c|}
\hline Model & Viscosity formula \\
\hline Einstein $^{[6]}$ & $\mu_{n f}=\mu_{f} \frac{1+0.5 \phi}{(1-\phi)^{2}}$ \\
\hline Brinkman $^{[7]}$ & $\mu_{n f}=\mu_{f} \frac{1}{(1-\phi)^{2.5}}$ \\
\hline Goddard-Miller $^{[8]}$ & $\mu_{n f}=\mu_{f} e^{2.5 \phi}$ \\
\hline Zuzovsky ${ }^{[9]}$ & $\mu_{n f}=\mu_{f}\left(1+\frac{2.5 \phi}{1+0.863 \phi-2.286 \phi^{5 / 3}}\right)$ \\
\hline Batchelor ${ }^{[10]}$ & $\mu_{n f}=\mu_{f}\left(1+2.5 \phi+6.25 \phi^{2}\right)$ \\
\hline Thomas $^{[11]}$ & $\mu_{n f}=\mu_{f}\left(1+2.5 \phi+10.5 \phi^{2}+0.00273 e^{16.6 \phi}\right)$ \\
\hline Lide Zhang ${ }^{[12]}$ & $\mu_{n f}=\mu_{f}\left\{1+2.5 \phi\left[1+\frac{1}{L \mu_{f} R^{2}}\left(\frac{\varepsilon \xi^{2}}{2 \pi}\right)\right]\right\}$ \\
\hline $\begin{array}{l}\text { De Kruit et al. }{ }^{[13]} \\
\text { Nielsen }\end{array}$ & $\begin{array}{c}\mu_{n f}=\mu_{f}(1+1.5 \phi) e^{\phi\left(1-\phi_{c}\right)} \\
\mathrm{b}\end{array}$ \\
\hline Green-Kubo ${ }^{[15]}$ & $\mu=\frac{V}{3 k_{B} T} \int_{0}^{\infty} \sum_{\alpha} \sum_{\beta}\left\langle P_{\alpha \beta}(0) P_{\alpha \beta}(t)\right\rangle \mathrm{d} t$ \\
\hline
\end{tabular}

Fan, Lu, et al. [16,17] used MD method to simulate the thermal conductivity and viscosity of $\mathrm{Al}_{2} \mathrm{O}_{3} / \mathrm{H}_{2} \mathrm{O}$ nanofluids The results show that the viscosity of nanofluids increases with the increase of the volume fraction of solid nanoparticles. Chen Jun [18] also obtained the same result, but he believed that the correlation of temperature was not significant.

Lou et al. [19] used equilibrium MS model to simulate the viscosity of $\mathrm{Al}_{2} \mathrm{O}_{3}-\mathrm{H}_{2} \mathrm{O}$ nanoparticle suspension, and found that the viscosity of the suspension increased with the decrease of nanoparticle size, the increase of concentration and the decrease of temperature. The research results of Chaoyang Zhong [20] showed that the viscosity of nanofluids increased with the decrease of particle size and aggregation. Lu and Fan [21] calculated the shear viscosities of alumina nanoparticles with different particle sizes in $\mathrm{H}_{2} \mathrm{O}$ and $\left(\mathrm{CH}_{2} \mathrm{OH}\right)_{2}$ by using MD method, and the results showed that the shear viscosities decreased with the increase of particle sizes. Rudyak and Krasnolutskii [22] used MD to measure the viscosity of nanofluids consisting of aluminum, lithium nanoparticles and liquid Ar, and reached the same conclusion. Lou and Yang [23] calculated the viscosity of $\mathrm{Al}_{2} \mathrm{O}_{3}$-water nanofluids using the Green-Kubo formula. The result also show that the viscosity increases as nanoparticles size decreases. Moreover, at lower temperature, the effect of the size of nanoparticles on the viscosity is more obvious. Therefore, it is necessary to use MD to study the effects of nanoparticle size and nanoparticle aggregation on the flow characteristics of nanofluids.

Zhang [24] used MD to study temperature effective on the viscosity of montmorillonite nanofluid and found that the viscosity of the same system decreased with increasing temperature, while for different systems, the difference of viscosity value narrowed with the increase of temperature. Zhao [25] explained the microscopic mechanism of nanofluid viscosification by means of MD simulation. The effect of nanoparticle percentage, temperature and

ISSN: 0010-8189 
pyroelectric nanoparticles on micelle formation of VES fracturing fluid were studied. The MD simulation results indicated that nanoparticles could adsorb wormlike limb bundles to form a network structure, which increased the viscosity, while too many nanoparticles destroyed the network structure, resulting in the decrease of nanofluid viscosity. At 400k, the micelles were separated from the common nanoparticles, resulting in the destruction of the network structure and the significant decrease of the viscosity of the nanofluids. However, pyroelectric nanoparticles could still adsorb micelles to form a network structure, which improved the high temperature viscosity of micelles.

Duan et al. [26] showed that aggregation would increase the viscosity of nanofluids and produce the characteristics of non-Newtonian fluids, while after ultrasonic treatment, the structure would be broken, the viscosity would decrease and the phenomenon of non-Newtonian fluids would disappear. Kang et al. [27] simulated the aggregation morphology of nanoparticles in $\mathrm{Cu}-\mathrm{Ar}$ nanofluids and calculated the viscosity of nanoparticles using the Green-Kubo method. The results showed that compared with the viscosity of pure liquid, the aggregation of nanoparticles increased the viscosity, and the different configurations of nanoparticles gave rise to different viscosity of nanofluid, but the viscosity of nanoparticles did not regularly with the particles size. Zhang et al. [28] studied the flow behavior of $\mathrm{Cu}$-Ar nanofluids, and they believed that dispersed copper nanoparticles in nanofluids would increase the overall viscosity, while agglomerated copper nanoparticles would only change the local flow characteristics.

Based on the current MD study of the viscosity of nanofluids, it can be seen that the viscosity of nanofluids increases with the increase of nanoparticle volume fraction, aggregation, temperature and nanoparticles size in the base fluid, mainly because:

a. When the volume fraction of nanoparticles in nanofluids increases, the interaction between nanoparticles increases and the interaction with the base liquid molecules decreases. In other words, the number of base liquid molecules around nanoparticles decreases, the stability decreases, and it is easy to aggregate, changing the fluid characteristics, producing the characteristics of non-Newtonian fluids, and increasing the viscosity.

b. As the temperature rises, Brownian motion of nanoparticles and base liquid molecules in the fluid is accelerated, molecular kinetic energy is increased, and intermolecular motion is promoted. As a result, intermolecular force and internal friction resistance between base liquid molecules and nanoparticles are weakened, which is manifested in reduced fluid viscosity [29].

c. The decrease in nanoparticles size and the increase in the total surface area would lead to the increase in the effective volume of nanoparticles in the solution, which may be the reason for the decrease in size and the increase in the viscosity of nanofluids [19].

By analyzing the properties of nanofluids and the viscosity calculation model, the method and importance of the stability and viscosity of nanoparticles in the molecular dynamic simulation of nanofluids were clarified, which laid a foundation for the subsequent multiphase interface and flow of nanoparticles.

\section{MD Simulation of Self-Assembled Nanoparticles at O/W Two-Phase Interface}

Self-assembly generally refers to the self-aggregation or orderly arrangement of components in a system after mixing in an appropriate proportion under appropriate conditions [30]. MD simulation research interface usually includes three aspects [31]: the process of charge transfer, the molecular orientation of the monolayer, and the intramolecular or intermolecular energy changes at the interface. The self-assembly behavior of nanoparticles at $\mathrm{O} / \mathrm{W}$ interface also includes the properties and quantity of nanoparticles, the type of base fluid, the temperature and salinity of base fluid, ion and electron transport, and the change of free energy.

In 1905, Einstein [32] published his famous statement on Brownian motion that for spherical particles larger than solvent molecules, the Stokes - Einstein (SE) equation could be used to predict the diffusion of particles in low-viscosity media, which laid a theoretical foundation for the subsequent diffusion of nanoparticles in solution.

ISSN: 0010-8189

(C) CONVERTER 2020

www.converter-magazine.info 
Yanmei Song et al. [33] found that the diffusion of nanoparticles in pure water and low viscosity oil was consistent with the SE equation, however, of the four nanoparticles studied by Wei et al. [34], the diffusion coefficients of two were greater than the corresponding values predicted by SE equation, and this deviation was attributed to the small particle size and anisotropy of the interface system.

Many scholars used MD simulation to calculate the interaction between different combinations of water phase and oil phase, which filled the gap in this part. In 1992, Benjamin [35] and Fernandes et al. [36] calculated the interface interaction of water-dichloroethane, and Benjamin researched the free diffusion of liquid molecules at the interface of water-dichloroethane. In 1993, Vanbuuren et al. [37] calculated the water-n-decane interface interaction. In 1995, Feller et al. [38] calculated the water-n-octane interface interaction. In 1999, Dang [39] calculated the water-dichloromethane interface interaction. In 2001 Senapati et al. [40] and in 2004 Moreira et al. [41] calculated water-carbon tetrachloride interface interactions. These simulations provided additional experimental molecular information, and the SE particle diffusion equation laid a solid theoretical foundation for subsequent MD studies of nanoparticle interactions at $\mathrm{O} / \mathrm{W}$ interface.

The self-assembling MD simulation of nanoparticles at $\mathrm{O} / \mathrm{W}$ interface has been studied and discussed.

All charged nanoparticles interact with charged particles to some extent, and Benjamin [42] discussed the adsorption of solute molecules and the transfer of ions and electrons across interfaces. Denzil S. Frost and Lenore L. Dar [43] believed that the self-assembly of nanoparticles at liquid-liquid interface would be significantly affected by the charge of a single nanoparticle, and the MD simulation results confirmed this point.

The particle size of nanoparticles is also a significant indicator that affects the behavior of O/W interface. Lin et al. [44] provided a method that facilitates the subsequent modification of nanoparticles to achieve rapid equilibrium at the fluid interface, proving that large particle sizes of nanoparticles at the interface replace small particle sizes. In the same year, it was proved that the nanoparticles were assembled in a disordered and dense monolayer structure at the interface of two immiscible liquids, and it was further demonstrated that the larger particles replaced small particles at the same rate as their adsorption energy. The results showde that the interfacial diffusion coefficient of the nanoparticles was 4 orders of magnitude slower than that of the particles in solution. Taking Pickering emulsion as an example, Lenore et al. [45] studied the multiphase interaction and self-assembled structure of nanoparticles at the trichloroethane (TCE)/ $\mathrm{H}_{2} \mathrm{O}$ interface. The first person directly observed the morphology of nanoparticles in liquid medium using environmental transmission electron microscopy (E-TEM), and the size of nanoparticles in liquid/liquid interface self-assembled structure was comparable to liquid molecules size. This provides the experimental basis for the follow-up research on the interaction of nanoparticles at the two-phase interface. Later, Mingxiang et al. [46] confirmed the influence of nanoparticles on the thickness of $\mathrm{H}_{2} \mathrm{O}$-TCE interface by density distribution analysis, but has no relation to the number of nanoparticles. Denzil et al. [47] proposed that some ionic liquids (ILs) have strong extraction capabilities, which can enable particles migrate across the interface without any shear force. This also confirms the self-diffusion of nanoparticles.

In recent years, through MD simulation studies, Shi et al. [48] proved that the free energy change theory could quantitatively predict the position and orientation of octahedral nanoparticles at the liquid/liquid interface, and the surface wettability (hydrophilic/hydrophobic ratio) of nanoparticles determined their most stable position and preferred orientation on the water/oil interface. Jin et al. [49] used MD simulation method to research the influence of salinity on $\mathrm{O} / \mathrm{W}$ interface.

ISSN: 0010-8189

(C) CONVERTER 2020

www.converter-magazine.info 

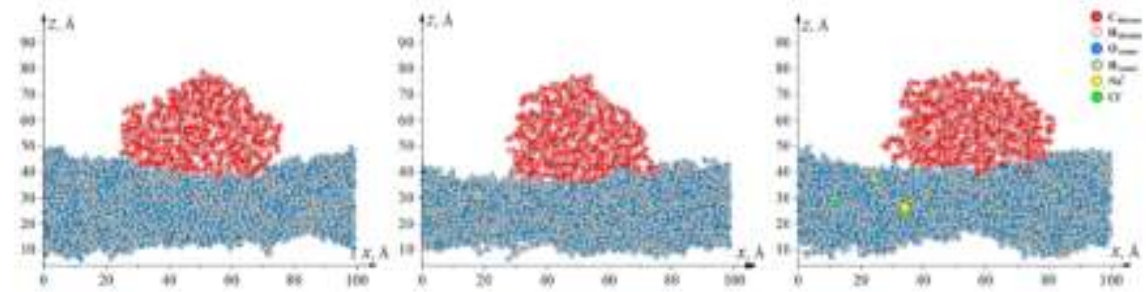

(a) $0 \mathrm{M}$

(b) $0.05 \mathrm{M}$

(c) $0.10 \mathrm{M}$
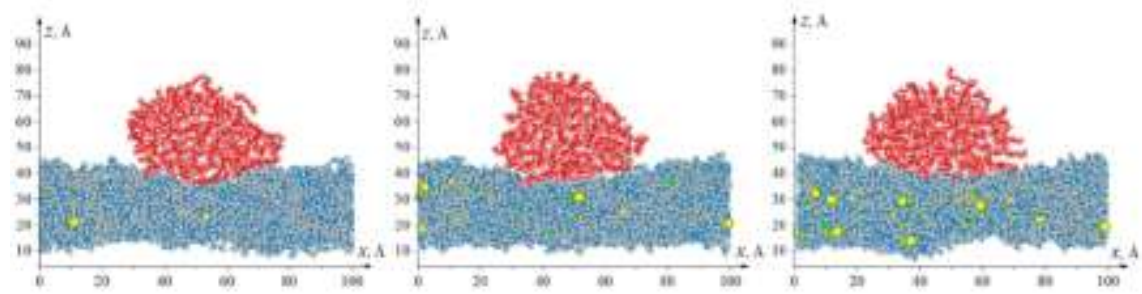

(d) $0.20 \mathrm{M}$

(c) $0.50 \mathrm{M}$

(f) $1.00 \mathrm{M}$

Fig 1. Diagram of a decane - mineralized water - vacuum three-phase system [49]

They calculated the bulk density distribution, RDF, interfacial thickness, and IFT of the O/W interface, and determined that the optimal salinity was $0.20 \mathrm{M}$, corresponding to the maximum interface thickness of the $\mathrm{O} / \mathrm{W}$ phase, which resulted in the minimum IFT and maximum contact angle of the $\mathrm{O} / \mathrm{W}$ interface. Conditions favorable to EOR.

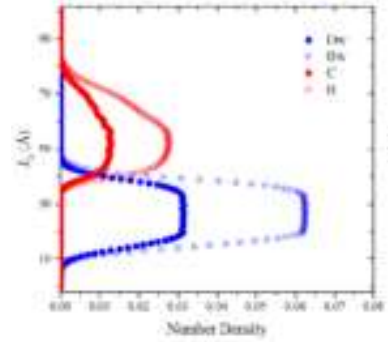

(a) $0.00 \mathrm{M}$

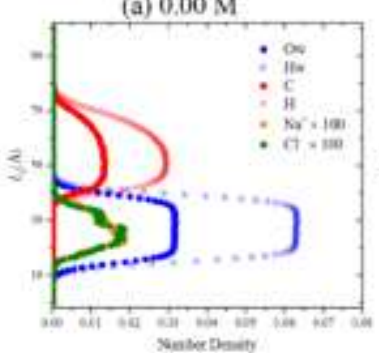

(d) $0,20 \mathrm{M}$

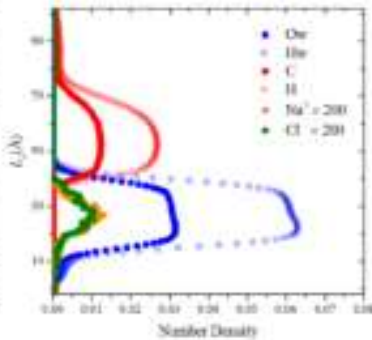

(b) $0.05 \mathrm{M}$

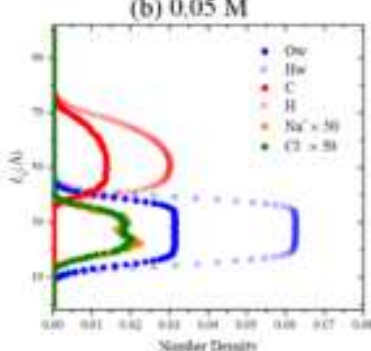

(c) $0.50 \mathrm{M}$

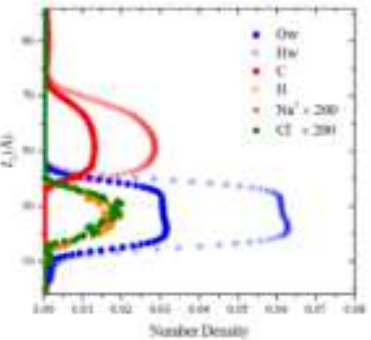

(c) $0.10 \mathrm{M}$

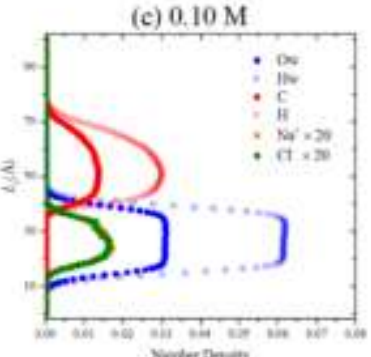

(i) $1.00 \mathrm{M}$

Fig 2. Numerical density diagram of the Z-axis direction of a decane - mineralized water - vacuum three-phase system [49]

We studied using MD simulation of nanoparticles in the $\mathrm{O} / \mathrm{W}$ two phase interface interaction mechanism, nanoparticles are emphatically analyzed the nature and quantity, base fluid salinity and the migration of ions and electrons as well as the free energy change, clear mechanism of nano particles in two-phase interface, for subsequent displacement process of nanofluids in microchannel research provides the theoretical basis.

\section{Simulation of Nanofluid Flow in Microscopic Pores}

ISSN: 0010-8189

(c) CONVERTER 2020

www.converter-magazine.info 
After water injection, a large amount of crude oil remains in the reservoir pores. Various methods, including chemical flooding [50] and gas flooding [51,52], have been applied to enhance oil recovery [53]. However, existing technology is difficult to remaining oil tapping potential [54-56]. The most direct and critical method is to change the nature of the fluid, that is, the quality of the fluid, to enhance the remaining oil exploration efficiency of the reservoir, such as improving the viscosity and reducing the interfacial tension. Given the important role of nanopores in connecting macropores and controlling reservoir permeability, understanding the flow dynamics of fluids under closed conditions, especially in rock nanopores, is critical to the design of displacement fluids. In ultra-low permeability reservoirs, nanopores with diameters of $0.5 \mathrm{~nm}$ to $100 \mathrm{~nm}$ account for $80 \%$ of the porosity of the reservoir rocks (depth $4500 \mathrm{~m}$ to $5600 \mathrm{~m}$ ) [57,58].

Fluids in confined nanopores behave differently from volumetric fluids [59,60]. In hydrophilic constraints, water molecules can form a stable layer near the wall, called immobile water, leading to an increase in fluid viscosity. The viscosity of artesian water decreases to the volume value with the increase of pipe diameter [61]. In contrast, under hydrophobic constraints, the viscosity of the fluid is inversely proportional to the diameter, that is, the transport of water is enhanced, which is of great significance for water purification [62] and $\mathrm{CO} 2$ utilization [63-66]. It is widely believed that the properties of constrained fluids are influenced by many factors, such as the addition of chemical additives, wettability, and the diameter of nanoparticles [67]. Recent experimental results show that nanofluids, as the basic fluids containing nanoparticles, have great potential in changing fluid viscosity, reducing $\mathrm{O} / \mathrm{W}$ interfacial tension, and changing the wettability of reservoir rock surface, and can be used to enhance oil recovery [68-74]. The fundamental understanding of these encouraging results is not yet complete, and the atomic mechanisms by which nanoparticles alter the properties of closed fluids need to be further elucidated.

Studying on fluid flow characteristics in finite channels, especially theoretical studies on MD simulation of complex multiphase systems at nanoscale $[75,76]$. Some of these models can verify that the analytical solutions are consistent with the experimental results $[77,78]$.

Wu et al. [67] studied the water flow in nanopores with different wettability values and sizes by MD simulation. They developed an accurate model for calculating slip length and viscosity in a finite channel. MD simulations were used to capture dynamic microscopic processes and reveal the interactions and mechanisms of various phenomena beyond the experimental resolution in the nanoscale [79-82]. M. Sedghi et al. [83] researched crude oil/brine displacement in calcite pores using a complete atomic model. They were able to determine the effects of determinants, including temperature, pressure, water salinity, and oil composition, on critical capillary pressure, and on controlling flow displacements. C. Chen et al. [84] studied the process of forced water flooding in capillary by using the multi-body dissipative particle dynamics (MDPD) method. The results show that the water displacement process was closely related to the wettability of capillary water and the miscibility of fluid. Therefore, it is of great significance to clarify the basic displacement mechanism of nanofluids under various conditions for enhancing oil recovery.

(a)

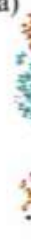

(c)

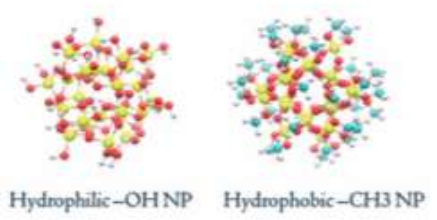

(b)

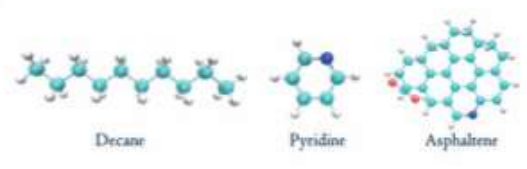

(d)

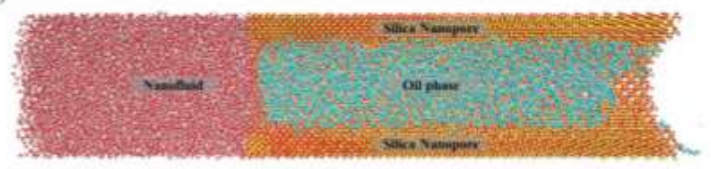

ISSN: 0010-8189

(C) CONVERTER 2020

www.converter-magazine.info 
Fig 3. Atom model: (a) Filled with n-decane molecule silica nanopore particles; (b) Three oils; (c) Hydrophilic and hydrophobic silica nanoparticles modified by - $\mathrm{OH}$ and $-\mathrm{CH}_{3}$, respectively; (d) Two-phase displacement system. The colors of the different atoms: O-red, H-white, Si-yellow, C-cyan, N-blue. [85]

Xiao et al. [85] conducted a series of MD simulations with all the atomic models to study the effects of nanoparticles and the different wettability values and the flow behavior of petroleum components (NPs) through nanopores in order to explore the dynamic flow performance and displacement mechanism of nanofluids in oil reservoirs. The results reveal the microscopic mechanism of fluid flow in mineral pores and provide design guidance for nanoparticles and nanofluid EOR.

\section{Conclusion and Prospect}

The application of nanofluid MD simulation in oil and gas field development has provided microscopic theoretical guidance for oil and gas field development and enhanced oil recovery. The following conclusions and considerations are drawn:

a. The stability of nanofluid is mainly affected by the following aspects: the interaction between nanoparticle and base solution, the properties of nanoparticle, the size and shape of nanoparticle, temperature, and the addition and type of dispersant.

b. The self-assembly behavior of nanoparticles at $\mathrm{O} / \mathrm{W}$ interface includes the properties and quantity of nanoparticles, the type of base fluid, the temperature and salinity of base fluid, ion and electron transport, and the change of free energy.

c. The quantitative relationship between displacement length, simulation time and interfacial tension under the influence of different pressure difference, temperature, rock wettability, solution salinity and other factors was studied by MD simulation, so as to provide guidance for simulation scheme design for enhanced oil recovery of spherical nanoparticle fluid.

d. MD simulation is applied in oilfield development, and its space and time scales are limited, which makes it impossible to carry out macro-scale and large-scale simulation. The simulation system is basically a single pure material system, which cannot fully consider the changes and influences of various factors on the experimental conditions.

e. Three-dimensional spherical particles smaller than a two-dimensional lamellar structure surface, therefore, between the microscopic properties, diffusion, adsorption, self-assembly and so on related dynamics behavior there are great differences in the MD simulation, also lack of $2 \mathrm{~d}$ nanoparticles in oil - solid - water distribution in the three-phase interface, and its application in oil - solid - water three-phase interface microscopic interaction research. This research will be an important direction of nanofluid MD simulation in oil and gas field development and application.

\section{Conflicts of Interest}

The authors declare no competing financial interest.

\section{Acknowledgements}

The authors express appreciation to Professor Jirui Hou and his group at the China University of Petroleum.

\section{References}

[1] B. J. Alder, T. E. Wainwright, "Phase transition for a hard sphere system," The Journal of Chemical Physics, vol. 27, pp. 1208-1209, 1957.

[2] U. S. Choi, "Enhancing thermal conductivity of fluids with nanoparticles," Developments and

ISSN: 0010-8189

(C) CONVERTER 2020 
Applications of Non-Newtonian Flows, ASME, NY, pp. 99-105, 1995.

[3] N. Wang, J. Chen, Q. S. An, et al, "Elementary research on the dispersion and stability of nanofluids by molecular dynamics simulations," Journal of Engineering Thermophysics, vol. 32, no. 07, pp. 1107-1110, 2011.

[4] D. Y. Qin, "Simulation of nanofluids heat transfer enhancement and flow characteristics with LBM," Dalian University of Technology, 2012.

[5] Z. Y. Ling, Y. T. Huang, Z. Q. Zhang, G. Q. Niu, G. G. Cheng, "Effect of surfactants on the stability of $\mathrm{Cu}-\mathrm{H} 2 \mathrm{O}$ and ZrO2-H2O nanofluids," Function Materials, vol. 46, no. 10, pp. 10100-10103+10109, 2015.

[6] M. E. Mackay, T. T. Dao, et al, "Nanoscale effects leading to non-einstein-like in viscosity," Nature Material, vol. 2, pp. 762-766, 2003.

[7] H. C. Brinkman, "The viscosity of concentrated suspensions and solutions," Journal of Chemical Physics, vol. 20, pp. 571-581, 1952.

[8] J. D. Goddard, et al, "Nonlinear effects in the theology of dilute suspensions," J Fluid Mech, vol. 28, pp. 657, 1967.

[9] M. Zuzovsky, et al, "Spatially periodic suspensions of convex particles in linear shear flows. III. dilute arrays of spheres suspended in newtonian fluids," Phys Fluids, vol. 26, pp. 1714, 1983.

[10] G. K. Batchelor, "The effect of brownian motion on the bulk stress in a suspension of spherical particles," J Fluid Mech, vol. 83, pp. 97, 1977.

[11] D. G. Thomas, "Transport characteristics of suspension: a note on the viscosity of newtonian suspensions of uniform spherical particles," Journal of Colloid Science, vol. 20, pp. 267-277, 1965.

[12] L. D. Zhang, J. M. Mou, "Nanomaterials and nanostructure," Beijing: Science Press, 2001.

[13] C. G. de Kruif, "Hard sphere colloidal dispersions: viscosity as a function of shear rate and volume fraction," J Chem Phys, vol. 83, pp. 4717, 1985.

[14] L. E. Nielsen, "Generalized equation for the elastic moduli of composite materials," J Appl Phys, vol. 41, pp. 4626, 1970.

[15] J. M. Haile, I. Johnston, A. J. Mallinckrodt, et al, "Molecular dynamics simulation: elementary methods," Computers in Physics, vol. 7, no. 06, pp. 625, 1993.

[16] Q. G. Fan, W. Q. Lu, "Simulation of thermal conductivity and viscosity of nanofluids by molecular dynamics (MD)," Journal of Engineering Thermophysics, vol. 25, no. 02, pp. 268-270, 2004.

[17] W. Q. Lu, Q. M. Fan, "Study for the particle's scale effect on some thermophysical properties of nanofluids by a simplified molecular dynamics method," Engineering Analysis with Boundary Elements, vol. 32, pp. 282-289, 2008.

[18] J. Chen, "Mechanism of transport properties in nanofluids by molecular dynamics simulations," Tsinghua University, 2011.

[19] Z .Lou, M .Yang. "Molecular dynamics simulations on the shear viscosity of Al2O3 nanofluids," Computers \& Fluids, vol. 117, pp. 17-23, 2015.

[20] C. Y. Zhong, "Aggregation and size effect on flow of nanoparticles by MD," Hebei University of Engineering, 2020.

[21] W. Q. Lu, Q. M. Fan, "Study for the particles scale effect on some thermophysical properties of nanofluids by a simplified molecular dynamics method," Engineering Analysis with Boundary Elements, vol. 32, pp. 282-289, 2008.

[22] V. Y. Rudyak, S. L. Krasnolutskii, "Simulation of the nanofluid viscosity coefficient by the molecular dynamic method,” Technical Physics, vol. 60, pp. 798-804, 2015.

[23] Z. Y. Lou, M. L. Yang, "Molecular dynamics simulations on the shear viscosity of A12O3 nanofluids," Computers \& Fluids, vol. 117, pp. 17-23, 2015.

[24] Y. Zhang, "Molecular simulations of interactions between water and T-O-T layered clay minerals," Southwest Petroleum University, 2016.

ISSN: 0010-8189

(C) CONVERTER 2020 
[25] X. H. Zhao, "The Study of engineering characteristics and molecular dynamics simulation on viscoelastic (VWS) fracturing fluids modified by nanoparticles," Zhejiang University, 2018.

[26] F. Duan, D. Kwek, A. Crivoi, "Viscosity affected by nanoparticle aggregation in Al2O3-water nanofluids," Nanoscale Research Letters, vol. 6, no. 1, pp. 248, 2011.

[27] H. B. Kang, Y. W. Zhang, M. Yang, L. Li, "Molecular dynamics simulation on effect of nanoparticle aggregation on transport properties of a nanofluid," Journal of Nanotechnology in Engineering and Medicine, vol. 3, pp. 021001-021006, 2012.

[28] Z. Q. Zhang, L. S. Yuan, Z. Liu, G. G. Cheng, H. F. Ye, J. N. Ding, "Flow behaviors of nanofluids in parallel-plate nanochannels influenced by the dynamics of nanoparticles," Computational Materials Science, vol. 145, pp. 184-190, 2018.

[29] G. J. Zhong, Y. L. Zhai, G. R. Bao, L. Li, "Analysis of factors influencing stability and viscosity of nanofluids," Journal of Materials Science \& Engineering, vol. 38, no. 01, pp. 74-80+87, 2002.

[30] R. Rajagopalan, "Curr opin in colloid \& interface cci," vol. 6, pp. 357-365, 2001.

[31] A. M. Stoneham, J. H. Harding, “Acta mater,” vol. 46, no. 7, pp. 2255-2261, 1998.

[32] Einstein, A. Ann. Phys. vol. 7, pp. 549, 1905.

[33] Y. M. Song, M. X. Luo, L. L. Dai, "Understanding nanoparticle diffusion and exploring interfacial nanotechnology using molecular dynamics simulations," Langmuir, vol. 26, no. 1, pp. 5-9, 2010.

[34] W. Gao, Y. Jiao, L. L. Dai, "The effects of size, shape, and surface composition on the diffusive behaviors of nanoparticles at/across water-oil interfaces via molecular dynamic simulations," vol. 8, no. 4, pp. 91, 2016.

[35] I. Benjamin., "Theoretical study of the water/1, 2-dichloroethane interface: structure, dynamics, and conformational equilibria at the liquid-liquid interface,” J. Chem. Phys. vol. 97, pp. 1432, 1992.

[36] P. A. Fernandes, M. N. D. S. Cordeiro, J. A. N. F. Gomes, "Molecular dynamics simulation of the water/1, 2-dichloroethane interface,” J. Mol. Struct.: Theochem, vol. 463, pp. 151, 1999.

[37] A. R. Vanbuuren, S. J Marrink., H. J. C. Berendsen, "A molecular dynamics study of the decane/water interface,” J. Phys. Chem. vol. 97, pp. 9206-9212, 1993.

[38] S. E. Feller, Y. H. Zhang, B. R. Brooks, "Constant pressure molecular dynamics simulation: the langevin piston method,” J. Chem. Phys. vol. 103, pp. 4613-4621, 1995.

[39] L. X. Dang, "Intermolecular interactions of liquid dichloromethane and equilibrium properties of liquid-vapor and liquid-liquid interfaces: a molecular dynamics study," J. Chem. Phys. vol. 110, pp. 10113, 1999.

[40] S. Spenapati, M. L. Berkowitz, "Computer simulation study of the interface width of the liquid/liquid interface,” Phys. Rev. Lett. vol. 8717, pp. 146101, 2001.

[41] N. H. Moreira, M. S. Skaf, "Structural characterization of the H2O/CCl4 liquid interface using molecular dynamics simulations,” Colloid Polym. Sci. vol. 128, pp. 81-85, 2004.

[42] I. Benjamin, "Molecular structure and dynamics at liquid-liquid interfaces," Annu. Rev. Phys. Chem. vol. 48, pp. 407, 1997.

[43] S. Denzil, L. D. Lenore, "Molecular dynamics simulations of charged nanoparticle self-assembly at ionic liquid-water and ionic liquid-oil interfaces," The Journal of Chemical Physics, vol. 136, 084706, pp. 1-6, 2012.

[44] Y. Lin, H. Skaff, T. Emrick, et al, "Nanoparticle assembly and transport at liquid-liquid interfaces," Science, vol. 299, pp. 226-229, 2003.

[45] L. D. Lenore, R. Sharma, C. Y. Wu, "Self-assembled structure of nanoparticles at a liquid-liquid interface, Langmuir," vol. 21, pp. 2641-2643, 2005.

[46] M. X. Luo, A. M. Oleg, Q. Zhu, et al, "Molecular dynamics simulation of nanoparticle self-assembly at a liquid-liquid interface," Langmuir, vol. 22, pp. 6385-6390, 2006.

[47] S. F. Denzil, M. Ngan, L. D. Lenore, "Spontaneous transport of microparticles across liquid-liquid interfaces," Langmuir, vol. 29, pp. 9310-9315, 2013. 
[48] W. X. Shi, Y. H. Lee, X. Y. Ling, et al, "Quantitative prediction of position and orientation for an octahedral nanoparticle at liquie/liquid interfaces," Nanoscale, vol. 31, no. 9, pp. 11239-11248, 2017.

[49] J. Zhao, G. C. Yao, B. R. Srinivasa, et all, "Molecular dynamics simulation of the salinity effect on the n-decane/water/vapor interfacial equilibrium," vol. 32, pp. 11080-11092, 2018.

[50] J. Lee, A. Nikolov, D. Wasan, "Effects of micellar structuring and solubilized oil on the kinetic stability of aqueous foams," Ind. Eng. Chem. Res, vol. 53, pp. 18891-18899, 2014.

[51] Y. Xiong, C. Wang, J. Jiang, H. Deng, "A simple method to calculate the viscosity of heavy oil saturated with supercritical $\mathrm{CO}_{2}$ using correlations,” Energy Fuels, vol. 30, pp. 2805-2812, 2016.

[52] Y. Yan, C. Li, Z. Dong, et al, "Enhanced oil recovery mechanism of $\mathrm{CO}_{2}$ water-alternating-gas injection in silica nanochannel,” Fuel, vol. 190, pp. 253-259, 2017.

[53] K. Falk, B. Coasne, R. Pellenq, et al, "Subcontinuum mass transport of condensed hydrocarbons in nanoporous media," Nat. Commun, vol. 6, pp. 6949, 2015.

[54] E. A. Taborda, C. A. Franco, M. A. Ruiz, et al, "Experimental and theoretical study of viscosity reduction in heavy crude oils by addition of nanoparticles," Energy Fuels, vol. 31, pp. 1329-1338, 2017.

[55] C. Negin, S. Ali, Q. Xie, “Application of nanotechnology for enhancing oil recovery - a review, Petroleum,” vol. 2, pp. 324-333, 2016.

[56] A. Bera, H. Belhaj, "Application of nanotechnology by means of nanoparticles in oil recovery - a comprehensive review,” J. Nat. Gas. Sci. Eng., vol. 34, pp. 1284-1309, 2016.

[57] J. M. de Almeia, C. R. Miranda. "Improved oil recovery in nanopores: nanoior," Sci. Rep., vol. 6, pp. 28128, 2016.

[58] T. J. Katsube, M. A. Williamson, "Effects of diagenesis on shale nano-pore structure and implications for sealing capacity," Clay Miner., vol. 29, pp. 451-461, 1994.

[59] L. Wang, M. S. H. Boutilier, P. R. Kidambi, et al, "Fundamental transport mechanisms, fabrication and potential applications of nanoporous atomically thin membranes," Nat. Nanotechnol., vol. 12, pp. 509-522, 2017.

[60] A. B. Farimani, N. R. Aluru, "Spatial diffusion of water in carbon nanotubes: from fickian to ballistic motion,” J. Phys. Chem. B., vol. 115, pp. 12145-12149, 2011.

[61] P. J. Feibelman, "Viscosity of ultrathin water films confined between aluminol surfaces of kaolinite: ab initio simulations,” J. Phys. Chem. C, vol. 117, pp. 6088-6095, 2013.

[62] K. Yang, J. Wang, X. Chen, et al, "Application of graphene-based materials in water purification: from the nanoscale to specific devices,” Environ. Sci.: Nano, vol. 5, pp. 1264-1297, 2018.

[63] H. G. Park, Y. Jung, "Carbon nanofluidies of rapid water transport for energy applications,” Chem. Soc. Rev., vol. 43, pp. 565-576, 2014.

[64] M. Heiranian, A. B. Farimani, N. R. Aluru, Water Desalination With a Single-Layer MoS2 Nanopore, Nat. Commun, 2015,6,8616.

[65] M. Ma, F. Grey, L. Shen, et al, "Water transport inside carbon nanotubes mediated by phonon-induced oscillating friction,” Nat. Nanotechnol, vol. 10, pp. 692-695, 2015.

[66] C. H. Lee, B. Tiwari, D. Zhang, et al, "Water purification: oil-water separation by nanotechnology and environmental concerns," Environ. Sci.: Nano, vol. 4, pp. 514-525, 2017.

[67] K. Wu, Z. Chen, J. Li, et al, "Wettability effect on nanoconfined water flow," Energy Fuels, vol. 114, pp. 3358-3362, 2017.

[68] B. Wei, Q. Li, F. Jin, et al, “The potential of a novel nanofluid in enhancing oil recovery,” Energy Fuels, vol. 30, pp. 2882-2891, 2016.

[69] D. Luo, F. Wang, J. Zhu, et al, "Nanofluid of graphene-based amphiphilic janus nanosheets for tertiary or enhanced oil recovery: high performance at low concentration,” Proc. Natl. Acad. Sci. U. S. A., vol. 113, pp. 7711-7716, 2016.

[70] A. D. N. Darsh, T. Wasan. "Spreading of nanofluids on solids," Nature, vol. 423, pp. 156-159.

[71] J. M. Berlin, J. Yu, W. Lu, et al, "Engineered nanoparticles for hydrocarbon detection in oilfield rocks," 
Energy Environ. Sci., vol. 4, pp. 505-509.

[72] M. D. Becker, Y. Wang, K. D. Pennell, et al, "A multi-constituent site blocking model for nanoparticle and stabilizing agent transport in porous media,” Environ. Sci: Nano, vol. 2, pp. 155-166, 2015.

[73] H. Zhang, A. Nikolov, D. Wasan, "Enhanced oil recovery (EOR) using nanoparticle dispersions: underlying mechanism and imbibition experiments," Energy Fuels, vol. 28, pp. 3002-3009, 2014.

[74] N. A. Ogolo, O. A. Olafuyi, M. O. Onyekonwu, "Presented in part at the SPE arabia section technical symposium and exhibition, ai-khobar," Saudi Arabia, 2012.

[75] D. Schebarchov, S. C. Hendy, "Uptake and withdrawal of droplets from carbon nanotubes," Nanoscale, vol. 3, pp. 134-141, 2011.

[76] E. Oyarzua, J. H. Walther, A. Mejia, et al, "Early regimes of water capillary flow in slit silica nanochannels," Phys. Chem. Phys., vol. 17, pp. 14731-14739, 2015.

[77] G. Martic, F. Centner, D. Seveno, et al, "A molecular dynamics simulation of capillary imbibition," Langmuir, vol. 18, pp. 7971-7976, 2002.

[78] N. Giovambattista, A. B. Almeida, A. M. Alencar, et al, "Validation of capillarity theory at the nanometer scale by atomistic computer simulations of water droplets and bridges in contact with hydrophobic and hydrophilic surface," J. Phys. Chem. C., vol. 120, pp. 1597-1608, 2016.

[79] H. Yan, S. Yuan, "Molecular dynamics simulation of the oil detachment process within silica nanopores,” J. Phys. Chem. C., vol. 120, pp. 2667-2674, 2016.

[80] H. Wu, J. Chen, H. Liu, "Molecular dynamics simulations about adsorption and displacement of methane in carbon nanochannels," J. Phys. Chem. C., vol. 119, pp. 13652-13657, 2015.

[81] S. Xiao, J. He, Z. Zhang, "Nanoscale deicing by molecular dynamics simulations," Nanoscale, vol. 8, pp. 14625-14632, 2016.

[82] J. Zhong, M. Kumar, J. S. Francisco, et al, "Insight into chemistry on cloud/aerosol water surfaces," Acc. Chem. Res., vol. 51, pp. 1229-1237, 2018.

[83] M. Sedghi, M. Piri, L. Goual, "Atomistic molecular dynamics simulations of crude oil/brine displacement in calcite mesopores," Langmuir, vol. 32, pp. 3375-3384, 2016.

[84] C. Chen, L. Zhuang, X. Li, et al, "A many-body dissipative particle dynamics study of forced water-oil displacement in capillary,” Langmuir, vol. 28, pp. 1330-1336, 2012.

[85] X. Wang, S. B. Xiao, Z. L. Zhang, et al, "Displacement," Environment Science Nano, vol. 5, pp. 2641-2650, 2018.

ISSN: 0010-8189 